respiratory distress or cardiac tamponade. ${ }^{1,2}$ Purulent pericarditis is an infection within the pericardial space. ${ }^{3}$ With the development of broad-spectrum antibiotics, the incidence of purulent pericarditis has decreased dramatically and has become rare in healthy infants and children. ${ }^{4}$ Of the small number of documented cases of purulent pericarditis in children in the literature, the most common organisms found are Staphylococcus aureus, Streptococcus pneumoniae, and Haemophilus influenzae. ${ }^{3}$ Streptococcus intermedius is not a common cause of pericarditis. ${ }^{3,4}$

The case presented is unique in several ways. First, purulent pericarditis in an otherwise healthy child is rare. Streptococcus intermedius is often not present with purulent pericarditis in adults and has not been previously reported as a pathogen in children with purulent pericarditis. In addition, children with a pericardial teratoma most often present with respiratory distress or clinical symptoms of cardiac tamponade. In contrast, our patient presented primarily with concern for an infectious process. This was not only an unusual case of purulent pericarditis in an otherwise healthy child; it was an unusual presentation of a pericardial teratoma as she had no evidence of clinical cardiac tamponade or respiratory distress. This is the first reported case of purulent pericarditis in the presence of a pericardial teratoma in a child. It is also the first reported case of purulent pericarditis with Streptococcus intermedius in a child.

\section{References}

1. Becker AE. Primary heart tumors in the pediatric age group: a review of salient pathologic relevant for clinicians. Pediatr Cardiol. 2000;21:317-23.

2. Gunther T, Schreiber C, Noebauer C, Eicken A, Lange R. Treatment strategies for pediatric patients with primary cardiac and pericardial tumors: a 30-year review. Pediatr Cardiol. 2008;29:1071-6.

3. Parikh SV, Memon N, Echols M, Shah J, McGuire DK, Keeley EC. Purulent pericarditis report of 2 cases and review of literature. Medicine. 2009; 88:52-65.

4. Tokuyasu H, Saitoh Y, Harada T, Touge H, Kawasaki Y, Maeda R, et al. Purulent pericarditis caused by the Streptococcus milleri group: a case report and review of the literature. Intern Med. 2009;48:1073-8.

\title{
Awake uniportal video-assisted thoracoscopic metastasectomy after a nasopharyngeal carcinoma
}

Carlos Galvez, MD, Sergio Bolufer, MD, Jose Navarro-Martinez, MD, DEAA, and Francisco Lirio, MD, Alicante, Spain

Video clip is available online.

A 70-year-old man with a previous nasopharyngeal carcinoma treated with chemoradiotherapy in 2011, was found to have 2 nodules in the left upper lobe at follow-up (Figure 1, A). A fine-needle aspiration biopsy of the bigger lesion led to a diagnosis of metastatic disease. We suggested an awake procedure and the patient signed written informed consent.

\section{SURGICAL TECHNIQUE}

A thoracic epidural catheter was inserted at the T4-T5 level with a single injection of $15 \mathrm{~mL}$ of bupivacaine $0.5 \%$ and left in place during the procedure, but removed

From the University General Hospital of Alicante, Alicante, Spain.

Disclosures: Authors have nothing to disclose with regard to commercial support.

Received for publication Sept 5, 2013; revisions received Oct 20, 2013; accepted for publication Oct 25, 2013; available ahead of print Dec 2, 2013.

Address for reprints: Carlos Galvez, MD, C/Pintor Baeza, 12. 03010, Alicante, Spain (E-mail: carlos.galvez.cto@gmail.com).

J Thorac Cardiovasc Surg 2014;147:e24-6

$0022-5223 / \$ 36.00$

Copyright (c) 2014 by The American Association for Thoracic Surgery

http://dx.doi.org/10.1016/j.jtcvs.2013.10.041 at the end of the operation. Pressure of carbon dioxide $\left(\mathrm{PaCO}_{2}\right)$ and oxygen $\left(\mathrm{PaO}_{2}\right)$ was measured during the surgery. Midazolam and fentanyl were administered intravenously to keep the patient calm, but under conscious sedation throughout the procedure. He was placed in right lateral decubitus position and continued breathing spontaneously (Figure 1, B). An emergency protocol had been developed.

A 5-cm single incision in the fifth intercostal space (uniportal video-assisted thoracoscopic surgery [VATS]) was performed resulting in a surgical pneumothorax with excellent lung collapse. Mild hypoxemia occurred with $88 \%$ oxygen saturation, but the patient remained asymptomatic (Figure 1,C). We liberated some adhesions with the ultrasonic scalpel (Sonicision, Covidien, Mansfield, Mass) and palpated both nodules manually in the upper lobe. A wedge resection was performed with EndoGIA thick loads (Autosuture, Norwalk, Conn) and the specimen was removed with a specimen bag (Figure 1,D). Analysis of frozen sections of the nodules showed $1 \mathrm{~cm}$ of macroscopic free margins. A 24-Fr chest drain was inserted through the single port and connected to suction under $10 \mathrm{~cm} \mathrm{H}_{2} \mathrm{O}$; the patient was asked to breathe deeply and cough to completely reexpand the lung. 


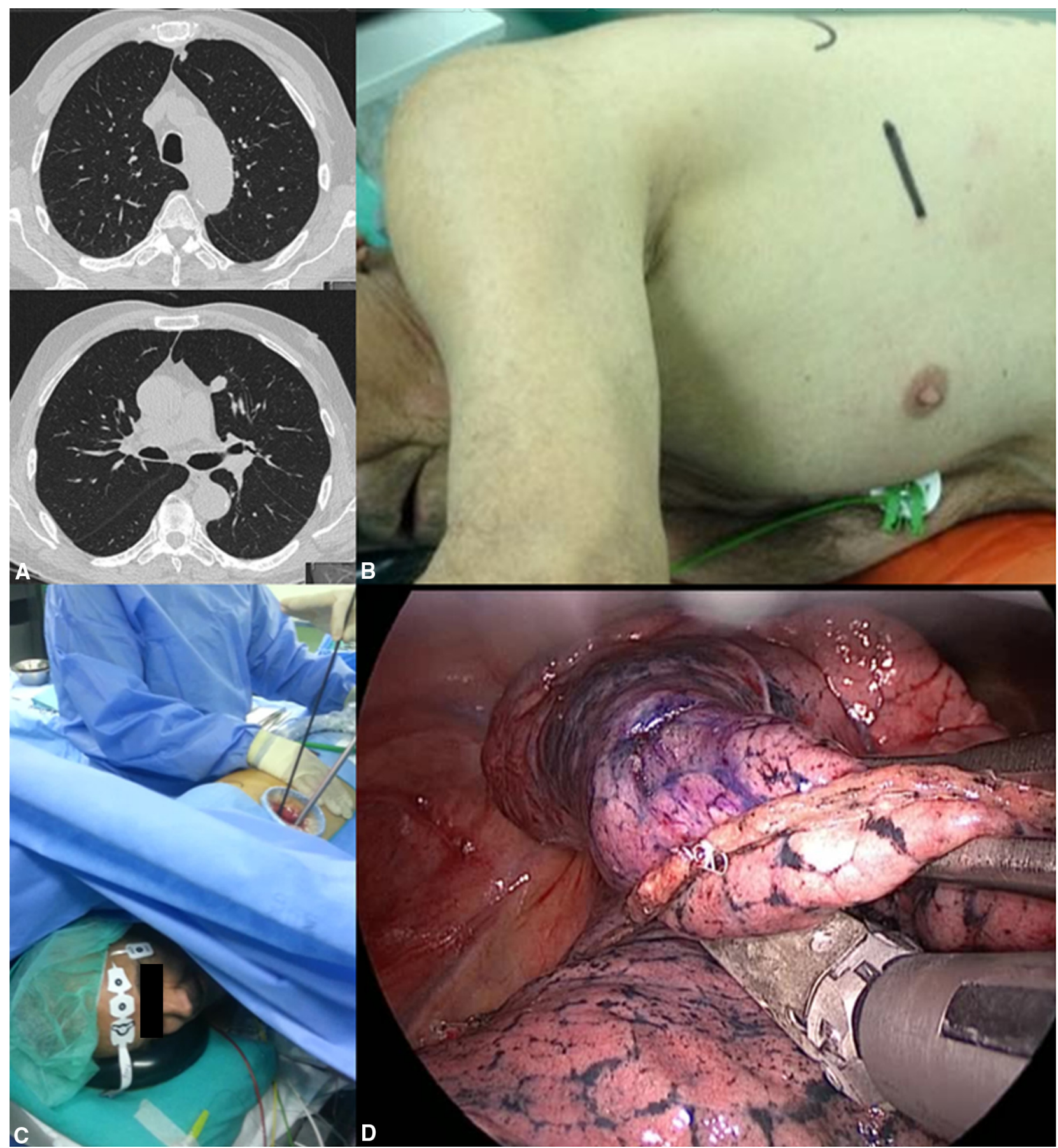

FIGURE 1. A, Computed tomography scan showing 2 peripheral nodules in the left upper lobe. B, Single incision of $5 \mathrm{~cm}$ in the fifth intercostal space. $\mathrm{C}$, The camera and the instruments are inserted through the single incision. The patient is conscious and breathing spontaneously. D, Resection of the nodules in the left upper lobe with a thick endostapler through the single incision.

During the procedure, the patient remained without dyspnea and was asked several times if he was comfortable with the operation. No hypercapnia was registered; the highest $\mathrm{PaCO}_{2}$ was $44 \mathrm{~mm} \mathrm{Hg}$. After the surgical pneumothorax was induced, he was administered oxygen with a venturi mask at $50 \%$ but oxygen saturation never fell below $88 \%$, and the patient was completely asymptomatic. Blood pressure, heart rate, and respiratory rate remained at normal values throughout the procedure. Total anesthesia time was 40 minutes.

The patient stayed in the recovery room for 3 hours, and we then removed the chest drain without air leak and the 
chest radiograph showed complete reexpansion of the lung. Once at the hospitalization unit, the patient started oral intake and walking; he was discharged home with a new chest radiograph 8 hours after the surgery showing no complications. He resumed normal activities the day after the surgery without any mishaps.

The final pathologic examination reported nasopharyngeal carcinoma metastasis (14 and $7 \mathrm{~mm}$, respectively) with a free margin of $0.9 \mathrm{~cm}$.

\section{DISCUSSION}

Thoracic surgery is evolving toward less invasive approaches. In recent years, uniportal VATS (single port) has gained approval in many centers, ${ }^{1}$ seeking reduction in postoperative pain compared with traditional VATS, even though there is still a lack of clinical trials comparing both approaches.

Many studies have shown the advantages of avoiding general anesthesia and orotracheal single-lumen intubation with mechanical ventilation, thus potentially decreasing the risk of postoperative complications. ${ }^{2}$ Several groups have also examined the safety and feasibility of performing pulmonary resections, such as metastasectomies and even lobectomies, in awake patients. ${ }^{3}$ The surgical pneumothorax created with the incision, specially with a uniportal incision, provides excellent lung collapse; thus, adjunctive measures such as endobronchial blockers are not necessary in most cases.

Our patient was carefully selected because his past history of chemoradiotherapy in the neck made doublelumen intubation more difficult. Surgical pneumothorax leads to mild hypoxemia and hypercapnia usually develops, but in most cases is tolerable to the patient. ${ }^{4}$ Epidural anesthesia proved to be an excellent method of thoracic anesthesia, allowing the diaphragm to be mobile, thereby counteracting the effects of paradoxic ventilation and mediastinal shift. Avoiding general anesthesia allows the patient to resume normal activities, such as drinking, eating, and walking, earlier; the patient can even be discharged the same day as the operation, reducing hospitalization time and costs. ${ }^{5}$

In conclusion, we believe that, in selected patients, a uniportal VATS incision combined with an epidural catheter with the patient breathing spontaneously, is a safe and feasible approach for performing pulmonary resections of peripheral metastatic nodules. It also can be incorporated in a fast-track program with the purpose of reducing the hospitalization time and the costs of the procedure. Prospective randomized clinical trials are needed to support this hypothesis.

\section{References}

1. Gonzalez-Rivas D, Paradela M, Fieira E, Velasco C. Single-incision video-assisted thoracoscopic lobectomy: initial results. J Thorac Cardiovasc Surg. 2013;143: $745-7$

2. Noda M, Okada Y, Maeda S, Sado T, Sakurada A, Hoshikawa Y, et al. Is there a benefit of awake thoracoscopic surgery in patients with secondary spontaneous pneumothorax? J Thorac Cardiovasc Surg. 2012;143:613-6.

3. Chen KC, Cheng YJ, Hung MH, Tseng YD, Chen JS. Nonintubated thoracoscopic ling resection: a 3-year experience with 285 cases in a single institution. J Thorac Dis. 2012;4:347-51.

4. Pompeo E, Mineo TC. Awake pulmonary metastasectomy. J Thorac Cardiovasc Surg. 2007;133:960-6.

5. Rocco G, Romano V, Accardo R, Tempesta A, La Manna C, La Rocca A, et al. Awake single-access (uniportal) video-assisted thoracoscopic surgery for peripheral pulmonary nodules in a complete ambulatory setting. Ann Thorac Surg. 2010; $89: 1625-7$

\title{
Aggressive infective endocarditis and the importance of early repeat echocardiographic imaging
}

\author{
Kyle Eudailey, MD, Jennifer Lewey, MD, Rebecca T. Hahn, MD, and Isaac George, MD, New York, NY
}

\footnotetext{
From the Division of Cardiothoracic Surgery and Department of Cardiology, and the Center for Interventional and Vascular Therapy, New York-Presbyterian Hospital, Columbia University Medical Center, and the Cardiovascular Research Foundation, New York, NY.

Disclosures: Authors have nothing to disclose with regard to commercial support.

Received for publication June 6, 2013; revisions received Sept 27, 2013; accepted for publication Oct 28, 2013; available ahead of print Dec 2, 2013.

Address for reprints: Isaac George, MD, Division of Cardiothoracic Surgery, New York-Presbyterian Hospital-Columbia University Medical Center, Milstein Hospital, 7GN-435, 177 Fort Washington Ave, New York, NY 10032 (E-mail: ig2006@columbia.edu).

J Thorac Cardiovasc Surg 2014;147:e26-8

$0022-5223 / \$ 36.00$

Copyright (C) 2014 by The American Association for Thoracic Surgery

http://dx.doi.org/10.1016/j.jtcvs.2013.10.069
}

The critical role of echocardiography in the assessment of suspected or known infective endocarditis (IE) has been well established. We present a report of aggressive aortic valve $(\mathrm{AV}) \mathrm{IE}$ in a 24-year-old man and reinforce the need for repeat echocardiographic imaging after negative results of examination if clinical suspicion remains high. ${ }^{1,2}$ Seven days after negative results of both transthoracic echocardiographic (TTE) and transesophageal echocardiographic (TEE) examinations, our patient had an annular abscess develop, with extensive local destruction necessitating emergency surgical repair. 